\title{
銅, 錫を含さアルミニウム合金の熱處理効果についで
}

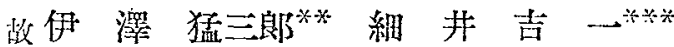

The late Takesabro Izawa and Yoshikaza Hosoi: On the Effect of Heat Treatment of Al Alloys Containing $\mathrm{Cu}, \mathrm{Sn}$. The present investigation was carried out to ascertain the effect of heat treatment on the natural age hardening and temper hardening of $\mathrm{Al}$ alloys containing $\mathrm{Cu}$ and $\mathrm{Sn}$ which had been used for bearing materials.

As these test pieces were prepared by addition of the mother alloys $\left(\mathrm{Cu}_{1} \mathrm{Sn}_{5} . \mathrm{Cu}_{3} \mathrm{Sn}\right.$ ) and $\mathrm{Mg}$ to $\mathrm{Al}$, the results obtained from the study of $\mathrm{Al}-\mathrm{Cu}_{6} \mathrm{Sn}_{3}, \mathrm{Al}_{-} \mathrm{Cu}_{3} \mathrm{Sn}$, and $\mathrm{Al}-\mathrm{Cu}_{3} \mathrm{Sn}_{5}-\mathrm{Mg}$ systems were as follows:

(1) All the alloys of these systens did not show a natural age hardening at room temperature, and the temper hardening was remarirable except the two alloys containing $2 \% \mathrm{Cu}_{j} \mathrm{Sn}_{j}$ or $\mathrm{Cu}_{3} \mathrm{Sn}$.

But the addition of $1.5 \% \mathrm{Mg}$ to these two alloys gave an influence upon the temper age hardening. From these results, it was certain that $\mathrm{Cu}$ and $\mathrm{Sn}$ were soluble in Al.

(2) By heating these natural aged alloys at $220^{\circ}$ for a short time, the hardness increased at first and decreased, and then increased.

This first hardening seemed to be a temper hardening with-out a certain precipitate and the second by it.

(Received April 17,1951)

\section{I. 緒 霄}

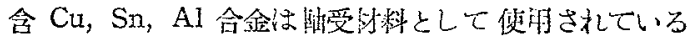

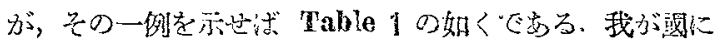
特いては数筫用プッシュ，ケルタット代用として，2〜3\%

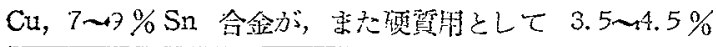

**元東京工業大學 ***金㳯大學工學部

* 1946 年 10 月本會大鲁仁一部滛表
$\mathrm{Cu}, 2 \sim 4 \% \mathrm{Sn}, 1 \sim 2 \% \mathrm{Mg}$ 合金亏゙健仴されている. かく

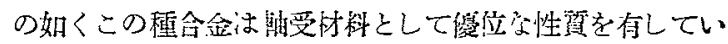

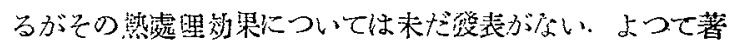

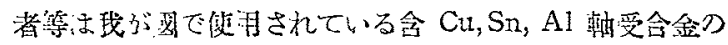

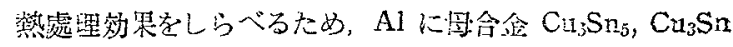

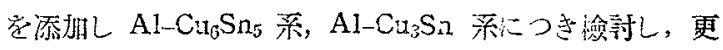
に $\mathrm{Mg}$ の影響狄らべるため $\mathrm{Al}-\mathrm{Cu}_{6} \mathrm{Sn}_{5}-\mathrm{Mg}$ 系こつい ても實羷在行つた。 
Table 1 Compositions and Designations of Al Bearing Alloys.

\begin{tabular}{|c|c|c|c|c|}
\hline \multirow{2}{*}{ Designations } & \multicolumn{4}{|c|}{ Compositions wt $\%$} \\
\hline & $\mathrm{Cu}$ & $\operatorname{Sn}$ & $\mathrm{Mg}$ & Al \\
\hline Fletcher \& Emperor & 7.5 & 0.25 & - & Bal \\
\hline L. 10 (England) & 10.0 & 1.25 & $\ldots$ & $" \prime$ \\
\hline L. 11 (England) & $6 \sim 8$ & 1 & - & " \\
\hline Fletcher's Alloy & 3 & 1 & $一$ & " \\
\hline Chi 701 (Japan) & $2 \sim 3$ & $7 \sim 9$ & -- & $"$ \\
\hline Chi $7(2$ (Japan) & $13.5 \sim 4.5$ & $2.0 \sim 4.0$ & $1 . C \sim 2 . C$ & $" \prime$ \\
\hline Mock Silver & 5.5 & 10.2 & $\cdots$ & $" 1$ \\
\hline Mc. Adams & 0 & 8 & - & $" 1$ \\
\hline Manhardts & 6.3 & 10 & 0.05 & $"$ \\
\hline Mc. Lure & 8.2 & $5 \sim 6$ & $\ldots$ & $" l$ \\
\hline
\end{tabular}

\section{II. 試粘の作成及び察驗方法}

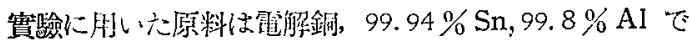

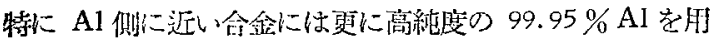

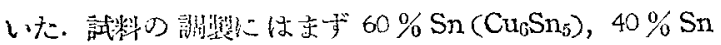

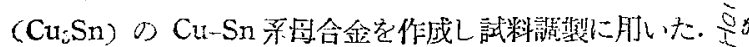

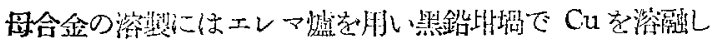

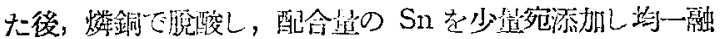

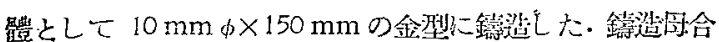

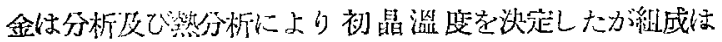

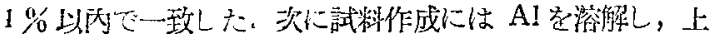

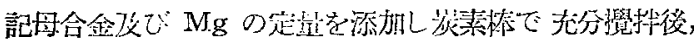

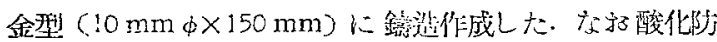

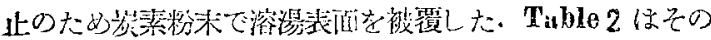

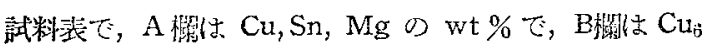

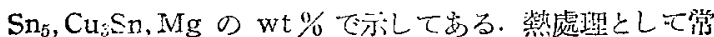

Table 2 No. and Compositions of Test Pieces A. Columnis Indicated by $\mathrm{Cu}, \mathrm{Sn}$ and $\mathrm{Mg}$ wt\%.

B. Column by $\mathrm{Cu}_{5} \mathrm{Sn}^{5}, \mathrm{Cu}_{3} \mathrm{Sn}$ and $\mathrm{Mg}$.

\begin{tabular}{|c|c|c|c|c|c|c|}
\hline \multirow{3}{*}{ No. } & \multicolumn{6}{|c|}{ Compositions wt $\%$} \\
\hline & \multicolumn{3}{|c|}{ A } & \multicolumn{3}{|c|}{$\mathrm{B}$} \\
\hline & Cii & Sn & $\mathrm{Mg}$ & $\mathrm{Cu}_{6} \mathrm{Sn}_{5}$ & $\mathrm{Cu}_{3} \mathrm{Sn}_{5}$ & $\mathrm{Mg}$ \\
\hline 1 & 0.8 & 1.2 & -- & 2 & 一 & - \\
\hline 2 & 2.0 & 3.0 & $\ldots$ & 5 & -- & - \\
\hline 3 & 3.2 & 4.8 & $\ldots$ & 8 & - & -- \\
\hline 4 & 4.0 & 6.0 & - & 10 & $\ldots$ & $\longrightarrow$ \\
\hline 5 & 4.8 & 7.2 & —. & 12 & - & - \\
\hline 6 & 6.0 & 9.0 & $\ldots$ & 15 & $\ldots$ & - \\
\hline 7 & 8.0 & 12.0 & - & 20 & -.- & - \\
\hline 8 & 1.2 & 0.8 & - & $\ldots$ & 2 & - \\
\hline 9 & 3.0 & 2.0 & - - & $\ldots$ & 5 & - \\
\hline 10 & 4.8 & 3.2 & $\ldots$ & ... & 8 & $\ldots$ \\
\hline 11 & 6.0 & 4.0 & - & - & 10 & - \\
\hline 12 & 7.2 & 4.8 & $\ldots$ & & 12 & - \\
\hline 13 & 9.0 & 6.0 & - & $\ldots$ & 15 & - \\
\hline 14 & 12.0 & 3.0 & -- & $\ldots$ & 20 & - \\
\hline 15 & c. 8 & 2 & 1.5 & 2 & $\ldots$ & 1.5 \\
\hline 16 & 2.0 & 3.0 & $"$ & 5 & -- & " \\
\hline 17 & 3.5 & 4.8 & " & 8 & 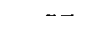 & $D$ \\
\hline 18 & 4.0 & 0.0 & "I & 10 & - & ir \\
\hline 19 & 9.8 & 7.2 & 77 & 12 & $\cdots$ & $"$ \\
\hline 20 & 6.0 & 9.0 & $" 1$ & 15 & - & " \\
\hline 21 & 8.0 & 12.0 & II & 20 & - & $" 1$ \\
\hline
\end{tabular}

湿時效，燒突特效處理を行い，更に復元處理をなし硬化現

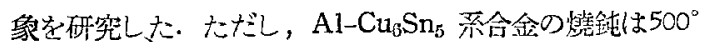

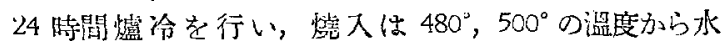

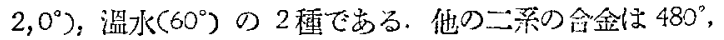

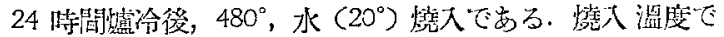

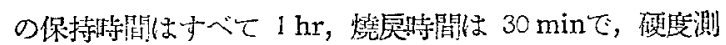

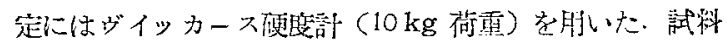
は $10 \mathrm{~mm} \times 10 \mathrm{~min}$ の㢄筒型でする。

\section{III. 货驗結累及び教察}

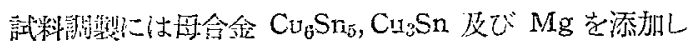

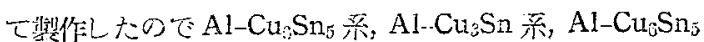

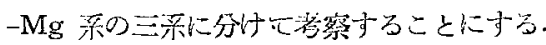

(1) A!-Cuj: $n_{5}$ 采 (No.1 No.7) 合金について Cu:

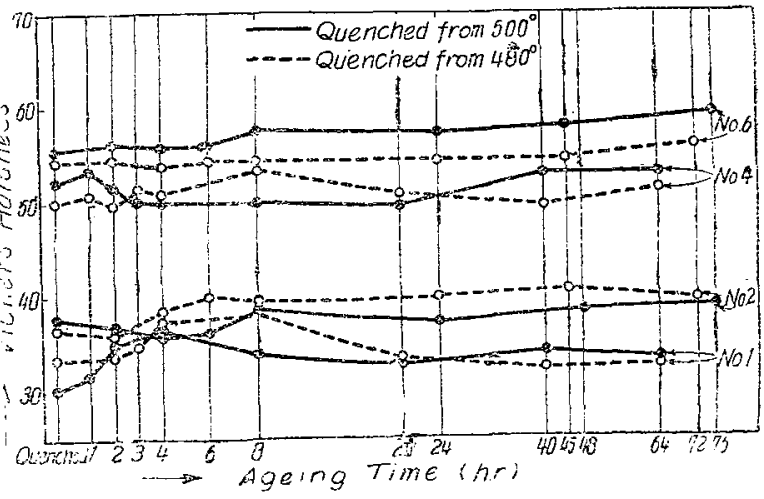

Fig. 1 Natural Ageing Effect on Vickers Hardness (No. 1, No. $420^{\circ}$ W. Q. No. $2 \mathrm{NQ}$. $\left.60^{\circ} \mathrm{W} . \mathrm{Q}\right)$.

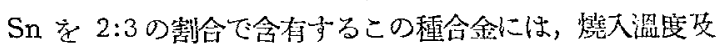

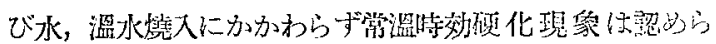

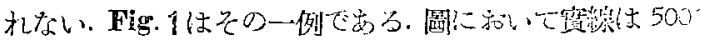

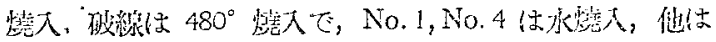

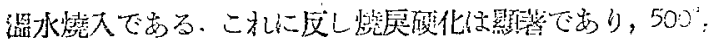

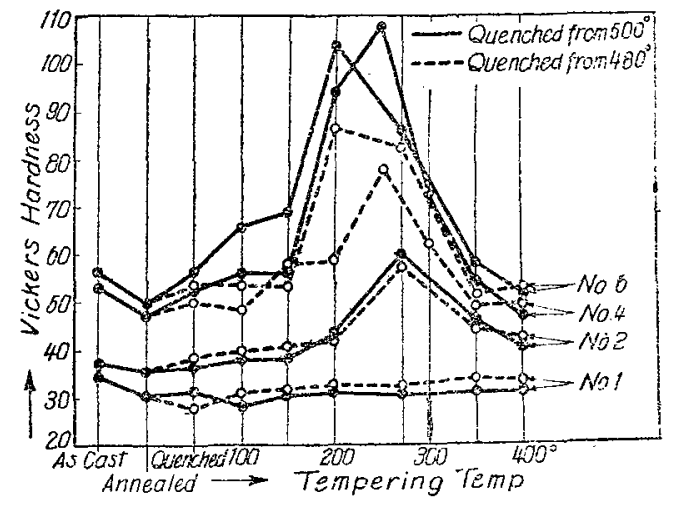

Fig. 2 Temper Ageing Effect on Vickers Hardness (No. $420^{\circ} \mathrm{W}$.

Q. No. 1, No. 2, No. $660^{\circ} \mathrm{W} . \mathrm{Q}$. )

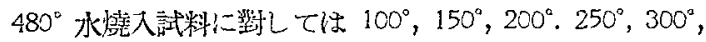

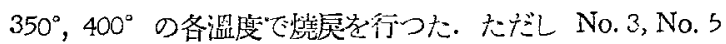


は $100^{\circ}, 150^{\circ}, 210^{\circ}, 250^{\circ}, 310^{\circ}, 370^{\circ}$ で燒㞔を行い. 溫水爟 入の場合は $100^{\circ}, 150^{\circ}, 200^{\circ}, 270^{\circ}, 350^{\circ}, 400^{\circ}$ での弉戻であ

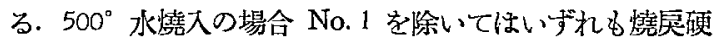

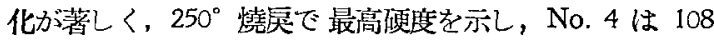
(V. H. N) を示した. また $480^{\circ}$ ，水燒入の場合 No.1 を 除きいずれも 210 300 致戻で最高硬度を示し No. 5 は 109 (V.H.N.) を示した.溫水燒入の場合は No.1 を除き

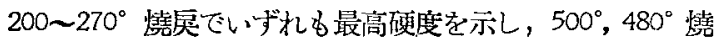
入共に No. 6 が $200^{\circ}$ 燒厣て各に 105,93 (V.H. N.)を示 した.以上のように燒戻硬化は濕著であり，燒入溫度，水燒 入，溫水燒入に上る美買は著しくないが，燒大溫度が高い 場合，硬化率が高い上うである. Fig. 2 はその一例を示 す、圖に捣いて䁈線は $500^{\circ}$, 硬線は $480^{\circ}$ 燒大で，No.4は

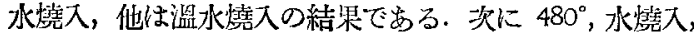
常溫時效後，220 で復元處理を行つたが，No.1を除き 1〜8 分の處理で硬度は上杽，8１0 分で一旦軟化，更に 長特䦥處理で 硬度は上昇する. Fig. 3 の No. 1, No. 2, No. 3, No. 4 はその一例である。

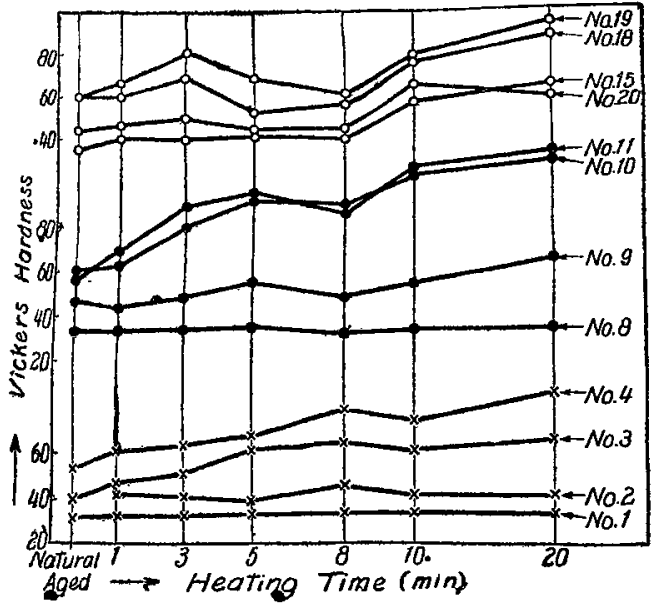

Fig. 3 Effect of Heating for a Short Time at $220^{\circ}$ on Vickers Hardness of Natural Agehardening Alloys after Quenching to $20^{\circ}$-Water from $480^{\circ}$

(2) Al-Cn $\mathrm{Cn}_{3} \mathrm{Sn}$ 系 (No. 8〜No. 14) 合金について Cu: Sn 3:2 の割合で含むこの種合金には㱠ど常溫時効現

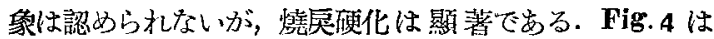
$480^{\circ}$ ，水熱入後， $150^{\circ}, 210^{\circ}, 250^{\circ}, 310^{\circ}, 370^{\circ}$ で焅戻處理安 行つた結果の一例であるが，No. 8 を除き $210^{\circ}$ ，焅戻で最 高硬度を示し，No. 10〜No.14 は 115 119 (V.H. N.) K 達した. 次に $480^{\circ}$ ，水焅入，常溫特效處理後，220 で復 元處理䘮行 と, No. 8 を除き約 5 分迄の處理で硬化し， 8 分で一旦軟化，更に 長時間處理で硬化する. Fig. 3 の No. 8, No. 9, No. 10, No. 11 はその一例である.

(3) Al-Ca $\mathrm{Sn}_{5}-\mathrm{Hg}$ 系 (No. 15 No. 21) 合金について $\mathrm{Al}-\mathrm{Cu}_{6} \mathrm{Sn}_{5}$ 系合金, No. 1 No. $7(\mathrm{Cu}: \mathrm{Sn}$ を 2:3 の制
合で含有）に $1.5 \% \mathrm{Mg}$ を添加したこの種合金にも殆ど

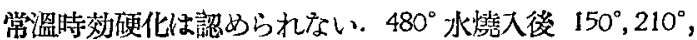

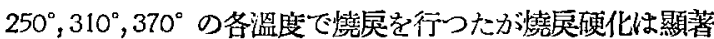
でいずれも $250^{\circ}$ 焅戻で最高硬度を示し，No. 17 は 88

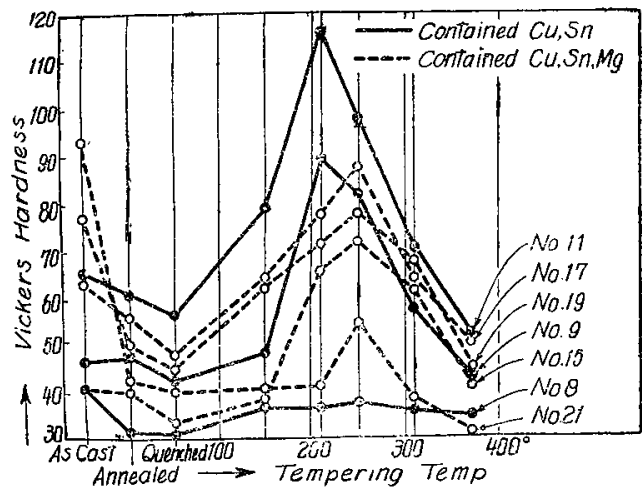

Fig. 4 Temper Ageing Effect on Vickars Hardness after Quenched to $20^{\circ}$ Water from $480^{\circ}$.

(V.H. N. )を示すが前記二系の合金に比し硬化率は低下し 燒戻硬化のなかつた No. 1 が Mg1.5\%涯加に上り硬化 寸る (No.15). Fig.4はこれを示寸，またNo.1〜No.14

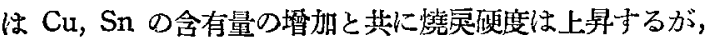
$\mathrm{Mg}$ の源加により定量以上の $\mathrm{Cu}, \mathrm{Sn}(3.2 \% \mathrm{Cu}, 4.8 \%$ Sn）を含有するものは燒㞔硬度は次第に低下寸る，次に $480^{\circ}$ 水淕入，常溫洔效後，復元處理を行 5 と 1 3 分迄 は硬化し，3〜8 分で一旦軟化，更に長洔暃處理で硬度は 上昇する. Fig. 3 にその一例を示す.

\section{IV. 螕括}

含 $\mathrm{Cu}, \mathrm{Sn}, \mathrm{Al}$ 合金として $\mathrm{Al}-\mathrm{Cu}_{6} \mathrm{Sn}_{5}, \mathrm{Al}-\mathrm{Cu}_{3} \mathrm{Sn}, \mathrm{Al}-$

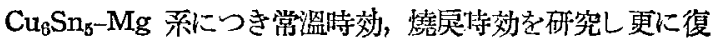
元處理による硬度督化を测定し次の諸結果を得た。

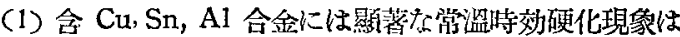
認められない，才なわち Al-Cu 系 Al 合金の常罚時效硬 化は $\mathrm{Sn}$ の添加により極めて微弱になる。

(2) $\mathrm{Cu}: \mathrm{Sn}$ を 2:3 の割合で含有する $\mathrm{Al}-\mathrm{Cu}_{6} \mathrm{Sn}_{5}$ 系合 金は $500^{\circ}$ 水燒入の場合 $250^{\circ}$ で, $480^{\circ}$ 水㷪入の場合 $210^{\circ}$ 燒戻で最高硬度を示し，溫水燒入の場合は燒入溫度にかか わらず $200^{\circ}$ 燒戻で最高硬度を示す。

(3) $\mathrm{Cu}: \mathrm{Sn}$ を $3: 2$ の割合で含有する $\mathrm{Al}_{-} \mathrm{Cu}_{3} \mathrm{Sn}$ 系合金 は $480^{\circ}$ 水燒大, $250^{\circ}$ で，また $\mathrm{Cu}: \mathrm{Sn}$ を $2: 3$ で含有し $1.5 \% \mathrm{Mg}$ 老添加した $\mathrm{Al}-\mathrm{Cu}_{6} \mathrm{Sn}_{5}-\mathrm{Mg}$ 采合金は $480^{\circ}$ 水 然入， $250^{\circ}$ 燒戻で最高硬度宗すが後者の硬化率は低い。

(4) $(\mathrm{Cu}+\mathrm{Sn})$ 量学 $2 \%$ 含有する Al 合金 (耳合金 $\mathrm{Cu}_{6} \mathrm{Sn}_{5}$ または $\mathrm{Cu}_{3} \mathrm{Sn}$ を2\%を含む合金)には燒戻硬化 は認められないが Mg 1.5\%添加すれば硬化が招こる。よ つて $\mathrm{Al}$ は $\mathrm{Cu}, \mathrm{Sn}$ を固溶し $\mathrm{Mg}$ の厓加に上り固溶限方 狹められるものと考えられる。

(5) $\mathrm{Cu}, \mathrm{Sn}$ 娄るいは $\mathrm{Cu}, \mathrm{Sn}, \mathrm{Mg}$ を含吉合金住 $220^{\circ}$ 
復元處理により短時間處理で硬化し，次に一旦軟化，更に 郎㸚授に對し樑く感謝の意を表すると共に博士の御宾程を 長持間處理で硬化する. 初期の硬化は岕る種の析出の伴わ 祈る. (附記) Al-Cu-Sn 三元采定性状態圖の研究(1)は

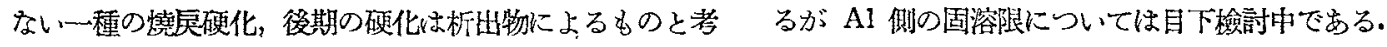
之る.

終に本研究にあたり種々御指導を戴した恩師故伊澤猛三

（1）传藤，矢島，本誌，8(1944), 